\title{
Cardiovascular and ventilatory acclimatization induced by chronic intermittent hypoxia: A role for the carotid body in the pathophysiology of sleep apnea
}

\author{
RODRIGO ITURRIAGA, SERGIO REY, and RODRIGO DEL RÍO
}

Laboratorio de Neurobiología, Facultad de Ciencias Biológicas. Pontificia Universidad Católica de Chile, Santiago, Chile

\begin{abstract}
Patients with obstructive sleep apnea (OSA) show augmented ventilatory, sympathetic and cardiovascular responses to hypoxia. The facilitatory effect of chronic intermittent hypoxia (CIH) on the hypoxic ventilatory response has been attributed to a potentiation of the carotid body (CB) chemosensory response to hypoxia. However, it is a matter of debate whether the effects induced by CIH on ventilatory responses to hypoxia are due to an enhanced CB activity. Recently, we studied the effects of short cyclic hypoxic episodes on cat cardiorespiratory reflexes, heart rate variability, and $\mathrm{CB}$ chemosensory activity. Cats were exposed to cyclic hypoxic episodes repeated during 8 hours for 4 days. Our results showed that CIH selectively enhanced ventilatory and carotid chemosensory responses to acute hypoxia. Exposure to $\mathrm{CIH}$ did not increase basal arterial pressure, heart rate, or their changes induced by acute hypoxia. However, the spectral analysis of heart rate variability of $\mathrm{CIH}$ cats showed a marked increase of the low/high frequency ratio and an increased variability in the low frequency band of heart rate variability, similar to what is observed in OSA patients. Thus, it is likely that the enhanced $\mathrm{CB}$ reactivity to hypoxia may contribute to the augmented ventilatory response to hypoxia.
\end{abstract}

Key terms: ventilatory acclimatization, carotid body, chemosensory activity, intermittent hypoxia, obstructive sleep apnea.

The carotid body (CB) chemoreceptor senses the arterial levels of $\mathrm{PO}_{2}, \mathrm{PCO}_{2}$, and $\mathrm{pH}$, and contributes to the ventilatory and cardiovascular regulation (Eyzaguirre and Zapata, 1984; Iturriaga et al., 1994a; Zapata and Iturriaga, 1997; Zapata and Larraín, 2005). In response to hypoxia, hypercapnia, and acidosis, the firing rate of chemosensory impulses increases in the carotid sinus nerve. The current model of CB chemoreception states that stimuli act upon chemoreceptor (glomus) cells, which are synaptically apposed to the sensory endings of petrosal ganglion neurons. It is accepted that hypoxia releases one -or more- excitatory transmitter(s) from glomus cells, which in turn increases the firing rate of chemosensory impulses in the nerve terminals of petrosal neurons (Iturriaga 2001; Iturriaga and Alcayaga, 2004). In addition, Eyzaguirre and colleagues proposed that electrical transmission plays an important role in $\mathrm{CB}$ chemoreception. Indeed, there are chemical and electrical connections between glomus cells and between glomus cells and the nerve endings of petrosal neurons (Eyzaguirre, 2005). In humans and mammals, the $\mathrm{CB}$ initiates the systemic ventilatory and cardiovascular adjustments to hypoxia. It is well known that exposure to sustained hypoxia (i.e. high altitude) augments the ventilatory response to acute hypoxia in humans and animals, a

Corresponding author: Dr. Rodrigo Iturriaga, Laboratorio de Neurobiología, Facultad de Ciencias Biológicas, P. Universidad Católica de Chile, Casilla 114D, Santiago, Chile. Tel.: (56-2) 686-2852, Fax: (56-2) 222-5515, E-mail: riturria@bio.puc.cl 
phenomenon known as ventilatory acclimatization (Bisgard, 2000). Ventilatory acclimatization induced by sustained hypoxia requires the presence of functional CBs, because it does not occur when the $\mathrm{CBs}$ are removed or the carotid sinus nerve is sectioned (Smith et al., 1986).

\section{CHRONIC INTERMITTENT HYPOXIA ENHANCES}

THE CAROTID BODY CHEMOSENSORY RESPONSE TO HYPOXIA

Exposure of humans or animals to sustained hypoxia for hours or days is normally known as chronic hypoxia. However, the most common pattern of hypoxic exposure in humans is chronic intermittent hypoxia (CIH), characterized by cyclic hypoxic episodes of short duration followed by normoxia. This hypoxic pattern is a feature of pathological conditions such as obstructive sleep apnea (OSA) and chronic obstructive pulmonary disease. The OSA syndrome is characterized by repeated episodes of partial or completes obstruction of the upper airway during sleep, which disturbs both ventilation and sleep architecture. The incidence of OSA (more than 10 apneas and hypopneas per hour) in middle-aged men and women is $5 \%$ and $3 \%$, respectively, but $24 \%$ of men and $9 \%$ of woman present 5 apneas per hour of sleep (Hla et al., 1994). During the collapse of the upper airway, the resulting hypoxia and hypercapnia stimulate the CB chemoreceptors, increasing the activity of respiratory muscles and enhancing vascular sympathetic tone and arterial pressure. Finally, the stimulation of CB chemoreceptors and pulmonary mechanoreceptors produces arousal and restores ventilation. The alternation of hypoxia and normoxia produces sleep fragmentation and drowsiness. In addition to the acute cardiovascular responses, approximately half of OSA patients develop arterial hypertension. The OSA syndrome is linked to metabolic, vascular, and genetic markers associated with an increased risk of cardiovascular disease. Endothelial dysfunctions, inflammation, disorders in lipid metabolism, and sympathetic activation have been proposed as potential pathogenic phenomena in OSA-linked hypertension (Quan and Gersh, 2004). Most of the information on effects of $\mathrm{CIH}$ on peripheral chemoreflex control of cardiovascular and respiratory systems has been obtained from studies performed on OSA patients. Several studies have shown that patients with OSA had enhanced ventilatory and cardiovascular reflex responses to acute hypoxia (Cistulli and Sullivan, 1994; Narkiewicz et al., 1998a; 1998b; 1999). Therefore, the facilitator effect of $\mathrm{CIH}$ on the hypoxic ventilatory response has been attributed to a potentiation of $\mathrm{CB}$ chemosensory responses to hypoxia (Narkiewicz et al., 1999; Loredo et al., 2001). Experiments performed in animal models show that $\mathrm{CIH}$ enhances the hypoxic ventilatory response (Ling et al., 2001) and produces long-term facilitation of respiratory motor activity (Peng and Prabhakar, 2003). Recently, Peng et al. (2001; 2003) found that basal CB discharges and chemosensory responses to acute hypoxia were larger in rats exposed to a $\mathrm{CIH}$ pattern consisting of short cyclic hypoxic episodes followed by normoxia, applied for 8 hours during 10 days. Using a protocol of short hypoxic episodes, we studied the early effects of $\mathrm{CIH}$ on cat chemosensory responses to hypoxia (Rey et al., 2004a; Del Río et al., 2004). We found that cats exposed to this $\mathrm{CIH}$ pattern $\left(\mathrm{PO}_{2} \sim\right.$ 75 Torr followed by normoxia during 8 hours for 4 days) showed an enhanced CB response to acute hypoxia. Moreover, we found that basal and hypoxic-induced $\mathrm{CB}$ chemosensory discharges were higher in $\mathrm{CIH}$ cats. Thus, present evidence supports that $\mathrm{CIH}$ enhances the $\mathrm{CB}$ chemosensory response to acute hypoxia.

MECHANISMS OF CAROTID BODY CHEMOSENSORY POTENTIATION BY CHRONIC INTERMITTENT HYPOXIA

Long-term exposure to sustained hypoxia for weeks or months produces CB hypertrophy and hyperplasia of glomus cells, also inducing angiogenesis (Heath and Smith, 1992; Wang and Bisgard, 2002). 
However, short-term exposure to $\mathrm{CIH}$ for 410 days does not produce hypertrophy and hyperplasia of glomus cells. Thus, it is likely that $\mathrm{CIH}$ may potentiate $\mathrm{CB}$ reactivity to acute hypoxia by changing the balance between excitatory and inhibitory transmitters or modulators within the chemoreceptor organ (Iturriaga and Alcayaga, 2004). There is evidence that sustained hypoxia for 2 weeks increases the levels of the CB excitatory peptide endothelin-1 and the expression of its receptor $\mathrm{ET}_{\mathrm{A}}$ in rat glomus cells (Chen et al., 2002). In addition, plasma concentration of endothelin-1 has been found to be elevated in OSA patients (Cistulli and Sullivan, 1994) and in rats exposed to $\mathrm{CIH}$ for a few days (Kanagy et al., 2001), suggesting that endothelin-1 may be involved in the enhanced cardiovascular response to hypoxia. In contrast, other inhibitory modulators of $\mathrm{CB}$ chemoreception, such as nitric oxide (Iturriaga, 2001; Valdés et al., 2003) and dopamine (Iturriaga et al., 1994b; 1996) also are up-regulated in the first weeks of chronic sustained hypoxia (Ye et al., 2002; Wang and Bisgard, 2002). Sustained hypoxia is a strong stimulus to increase catecolaminergic pathways in glomus cells. Prolonged and short exposure to sustained hypoxia increases the activity of tyrosine hydroxylase and the levels of dopamine in the CB (Hanbauer, 1977; Czyzyk-Krzeska et al., 1992). However, effects of CIH on the $\mathrm{CB}$ catecholaminergic pathway are smaller and delayed as compared to those induced by sustained hypoxia (Hui et al., 2003). Thus, effects of CIH on the expression of catecholaminergic enzymes in the glomus cells are transient and small compared with the effects of sustained hypoxia, suggesting that reduced dopaminergic induction by intermittent hypoxia in $\mathrm{CB}$ may contribute to the enhanced chemosensory response to hypoxia. Recently, Peng et al., (2003) found evidence involving oxygen radicals in the $\mathrm{CB}$ chemosensory potentiation induced by $\mathrm{CIH}$. They found that treatment with a superoxide anion scavenger prevents rat $\mathrm{CB}$ chemosensory potentiation induced by $\mathrm{CIH}$. In addition, the activity of the aconitase enzyme decreased in glomus cells compared with controls, and the activity of the complex I of the mitochondrial electron transport chain is inhibited, suggesting that mitochondria is one of the sources of reactive oxygen species. These observations indicate that the increased generation of these molecules may contribute to $\mathrm{CB}$ chemosensory potentiation induced by $\mathrm{CIH}$.

\section{EFFECTS OF CHRONIC INTERMITTENT HYPOXIA ON THE VENTILATORY SYSTEM}

Exposure to sustained hypoxia progressively increases both chemosensory and ventilatory responses to acute hypoxia in 4 hours in goats to 10 days in rats (Nielsen et al., 1988; Bisgard, 2000). In humans, mild hypoxia maintained for 8 hours produces hyperventilation and increases the reactivity of the reflex ventilatory response to acute hypoxia (Fatemian et al., 2001). In contrast, less is known about the effects of $\mathrm{CIH}$ on ventilatory control and $\mathrm{CB}$ function. $\mathrm{CIH}$ is associated with an augmented hypoxic ventilatory response in OSA patients and in animal models. Clearly, OSA patients show enhanced hypoxic ventilatory responses, however, in some studies a normal or even attenuated hypoxic ventilatory response also has been observed in patients with a prolonged OSA history (Costes et al., 1995; Osanai et al., 1999). Nonetheless, a main problem with these studies is that peripheral CB reflexes may be impaired by comorbidities such as obesity, aging, hypertension, and application of continuous positive airway pressure to treat the apneas. In a controlled study, performed in patients with recently diagnosed OSA without treatment, Narkiewicz et al., (1999) found that reflex ventilatory, sympathetic and cardiovascular responses to acute hypoxia were enhanced. More recently, Loredo et al., (2001) found that hypertensive patients with OSA present higher basal tidal volume, suggesting that the peripheral $\mathrm{CB}$ chemosensory drive is enhanced. Studies performed in animal models have shown dissimilar effects of $\mathrm{CIH}$ on the hypoxic ventilatory response. Ling et al. (2001) 
reported that phrenic response to acute hypoxia is enhanced in rats exposed to 5 min of $\sim 10 \% \mathrm{O}_{2}$, followed by $5 \mathrm{~min}$ of air, 12 hours/night during 7 nights. Similarly, Reeves et al. (2003) found that rats exposed to a CIH pattern consisting of alternating episodes of room air and $\sim 10 \% \mathrm{O}_{2}$ for $90 \mathrm{~s}$ for 30 days, showed an enhanced hypoxic ventilatory response. However, Greenberg et al. (1999) did not find any difference in ventilatory responses to hypoxia in rats exposed $30 \mathrm{~s}$ to $7 \% \mathrm{O}_{2}$ followed by $30 \mathrm{~s}$ of normoxia for 8 hours/day during 10 days. In a recent study, we (Rey et al., 2004a) found that four days of $\mathrm{CIH}$ increased cat basal tidal volume and inspiratory minute volume and potentiated the increase of these variables to acute hypoxia $\left(\mathrm{PO}_{2}<100\right.$ Torr). Thus, our results show that the enhanced hypoxic ventilatory response correlates with the potentiation of $\mathrm{CB}$ chemosensory responses to acute hypoxia. Therefore, experimental and clinical studies indicate that the initial response to $\mathrm{CIH}$ is an augmented ventilatory response to hypoxia. However, after long-term exposure to $\mathrm{CIH}$, the ventilatory response to hypoxia seems to be attenuated. Indeed, in an animal model of OSA produced by the telemetric occlusion of the upper airway in dogs, Kimmof et al. (1997) found that after 3 months of $\mathrm{CIH}$ dogs showed blunted ventilatory responses to hypoxia. This pattern of response to intermittent hypoxia is similar to what is observed in humans and animals exposed to high altitude hypoxia for long periods (Moore, 2000; Santolaya et al., 1989). Thus, one of the initial physiological responses to $\mathrm{CIH}$ is an enhanced ventilatory response that would allow a compensation for the cyclic hypoxic challenge, therefore improving survival. The attenuation of the enhanced ventilatory response observed in long-term exposure to $\mathrm{CIH}$ resembles the physiological acclimatization to sustained hypoxia. Since the hypoxic stimulation of the $\mathrm{CB}$ contributes to the arousal, the attenuation of the capacity to hyperventilate may reduce the strength of the response to terminate the apnea (Lahiri, 1994). García-Río et al. (2000) classified patients with OSA in three groups: normotensive, nocturnal hypertensive, and diurnal hypertensive. The ventilatory response to acute hypoxia was larger in the group of diurnal hypertensive patients than the nocturnal hypertensives and normotensive OSA patients. These results show that the magnitude of the enhanced ventilatory response to hypoxia is correlated with the increase in blood pressure, which is compatible with different degrees of $\mathrm{CB}$ responsiveness to hypoxia in OSA patients.

\section{EFFECTS OF CHRONIC INTERMITTENT HYPOXIA ON THE CARDIOVASCULAR SYSTEM}

Patients with OSA and animals exposed to $\mathrm{CIH}$ show enhanced renal sympathetic output, vascular reactivity, and systemic hypertension (Greenberg et al., 1999; Fletcher et al., 1995; Smith and Muenter, 2000; Somers et al., 1995). The hypertension has been attributed to an increased sympathetic outflow due to the repetitive hypoxic $C B$ stimulation. Indeed, the denervation of the $\mathrm{CB}$ prevents the hypertension induced by CIH (Fletcher et al., 1992). In fact, Fletcher et al. (1992) found an elevated arterial pressure in rats after 35 days of $\mathrm{CIH}$ exposure, but not after 10 days. In contrast, Sica et al. (2000) and Peng et al. (2003) found that systolic arterial pressure increases in rats after 7 days of CIH. We found that four days of intermittent hypoxia in cats were not enough to increase basal arterial pressure and cardiovascular responses to hypoxia (Rey et al., 2004a). However, we found that the spectral analysis of heart rate variability (RR-interval data) shows that sympathetic modulation of heart rate is early augmented by $\mathrm{CIH}$. Indeed, we found that the $\mathrm{LF} / \mathrm{HF}$ ratio was significantly higher in $\mathrm{CIH}$ cats $(2.4 \pm 0.1)$ as compared to control cats $(0.6 \pm 0.1)$. The spectral analysis of RR-interval data indicates a clear effect of $\mathrm{CIH}$ that resembles what is observed in OSA patients. In fact, patients with long or recently diagnosed OSA have an increased $\mathrm{LF} / \mathrm{HF}$ ratio and a relative predominance of the LF component of heart rate variability, with a reduced $\mathrm{HF}$ component (Shiomi et al., 1996; Narkiewicz et al., 1998a). In our model of $\mathrm{CIH}$, we 
observed that the exposure to cyclic hypoxic episodes increases the LF component with a simultaneous reduction of the HF component (Rey et al., 2004a). Thus, cats exposed to $\mathrm{CIH}$, like OSA patients, show an increased $\mathrm{LF} / \mathrm{HF}$ ratio suggesting the existence of early changes in sympathetic control of heart rate. Nevertheless, these changes appear in cats after 4 days of exposure to $\mathrm{CIH}$, compared to OSA patients that normally have a longer history of hypoxic exposure during sleep. It is widely accepted that the $\mathrm{LF} / \mathrm{HF}$ ratio is a measure of autonomic influences on heart rate variability (Task Force, 1996). The LF and HF components are related to autonomic influences on heart rate; the HF component has been related to cardiac parasympathetic efferent activity; and the LF component has been related to sympathetic cardiac efferences (Task Force, 1996).

\section{CONCLUSION}

The available experimental and clinical evidence suggests that the $\mathrm{CIH}$ pattern of short episodes of hypoxia followed by normoxia selectively enhances the CB chemosensory and ventilatory responses to hypoxia, suggesting that the $\mathrm{CB}$ plays an essential role in the enhanced ventilatory and cardiovascular responses observed in animals and OSA patients.

\section{ACKNOWLEDGEMENTS}

To Dr. Patricio Zapata for teaching us the love for chemoreceptor physiology, for the guiding role he played in our scientific careers and for his continuous support. This work was supported by grant FONDECYT 1030330 from the National Fund for Scientific and Technological Development of Chile.

\section{REFERENCES}

BISGARD GE (2000) Carotid body mechanisms in acclimatization to hypoxia. Respir Physiol 121: 237246

CHEN J, HE L, DINGER B, STENSAAS L, FIDONE S (2002) Role of endothelin and endothelin A-type receptor in adaptation of the carotid body to chronic hypoxia. Am J Physiol 282: L1314-1323

CISTULLI PA, SULLIVAN CE (1994) Pathology of sleep apnea. In: Sleep and Breathing. SAUNDERS NA, SULLIVAN CE (eds) New York: Marcel Decker. pp: 405-448

COSTES F, COURT-FORTUNE I, FOURNEL P, VERGNON JM, EMONOT A, GEYSSANT A (1995) Study of chemosensitivity in patients believed to have sleep apnea syndrome. Rev Mal Respir 12: 359-364

CZYZYK-KRZESKA MF, BAYLISS DA, LAWSON EE, MILLHORN DE (1992) Regulation of tyrosine hydroxylase gene expression in the rat carotid body by hypoxia. J Neurochem 58: 1538-1546

DEL RÍO R, REY S, ARIAS P, ALCAYAGA J, ITURRIAGA R (2004) Chronic intermittent hypoxia enhances chemosensory and ventilatory responses to acute hypoxia. Biol Res 37: R-90

EYZAGUIRRE C, ZAPATA P (1984) Perspectives in carotid body research. J Appl Physiol 57: 931-957

EYZAGUIRRE C (2005) Chemical and electric transmission in the carotid body chemoreceptor complex. Biol Res 38: 341-345

FATEMIAN M, KIM DY, POULIN MJ, ROBBINS PA (2001) Very mild exposure to hypoxia for $8 \mathrm{~h}$ can induce ventilatory acclimatization in humans. Pflugers Arch 441: 840-843

FLETCHER EC, LESSKE J, BEHM R, MILLER CC $3^{\text {rd }}$, STAUSS H, UNGER T (1992) Carotid chemoreceptors, systemic blood pressure, and chronic episodic hypoxia mimicking sleep apnea. J Appl Physiol 72: 1978-1984

FLETCHER EC, BAO G, MILLER CC III (1995) Effect of recurrent episodic hypocapnic, eucapnic, and hypercapnic hypoxia on systemic blood pressure. J Appl Physiol 78: 1516-1521

GARCÍA-RÍO F, RACIONERO MA, PINO JM, MARTINEZ I, ORTUNO F, VILLASANTE C, VILLAMOR J (2000) Sleep apnea and hypertension. Chest 117: 1417-1425

GREENBERG, HE, SICA A, BATSON D, SCHARF SM. (1999) Chronic intermittent hypoxia increases sympathetic responsiveness to hypoxia and hypercapnia. J Appl Physiol 86: 298-305

HANBAUER I (1977) Regulation of tyrosine hydroxylase in carotid body. Adv Biochem Psychopharmacol 16: 275-280

HEATH D, SMITH P (1992) Diseases of the Human Carotid Body. London: Springer-Verlag. pp: 205

HLA KM, YOUNG TB, BIDWELL T, PALTA M, SKATRUD JB, DEMPSEY J (1994) Sleep apnea and hypertension. A population-based study. Ann Intern Med 120: 382-388

HUI AS, STRIET JB, GUDELSKY G, SOUKHOVA GK, GOZAL E, BEITNER-JOHNSON D, GUO SZ, SACHLEBEN LR, HAYCOCK JW, GOZAL D, CZYZYK-KRZESKA MF (2003) Regulation of catecholamines by sustained and chronic intermittent hypoxia in neuroendocrine cells and sympathetic neurons. Hypertens 42: 1130-1136

ITURRIAGA R (2001) Nitric oxide and carotid chemoreception. Biol Res 34: 135-139

ITURRIAGA R, ALCAYAGA J (2004) Neurotransmission in the carotid body: Transmitters and modulators between glomus cells and petrosal ganglion nerve terminals. Brain Res Rev 47: 46-53

ITURRIAGA R, ALCAYAGA J, ZAPATA P (1996) Dissociation of hypoxia-induced chemosensory responses and catecholamine efflux in the cat carotid body superfused in vitro. J Physiol Lond 497: 551-564 ITURRIAGA R, LARRAÍN C, ZAPATA P (1994a) Phrenic 
nerve activity during artificial ventilation at different body temperatures and its relationships with carotid chemosensory activity. Biol Res 27: 145-157

ITURRIAGA R, LARRAIN C, ZAPATA P (1994b) Effect of domperidone blockade upon carotid chemosensory activity and its hypoxia-induced excitation. Brain Res 663: $145-154$

KANAGY NL, WALKER BR, NELIN LD (2001) Role of endothelin in intermittent hypoxia-induced hypertension. Hypertension 37: 511-515

KIMOFF RJ, BROOKS D, HORNER RL, KOZAR LF, RENDER-TEIXEIRA CL, CHAMPAGNE V, MAYER P, PHILLIPSON EA (1997) Ventilatory and arousal responses to hypoxia and hypercapnia in a canine model of obstructive sleep apnea. Am J Respir Crit Care Med 156: 886-894

LAHIRI S (1994) Carotid body chemoreception: Mechanisms and dynamic protection against apnea. Biol Neonate 65: 134-139

LING L, FULLER DD, BACH KB, KINKEAD R, OLSON EB JR, MITCHELL GS (2001) Chronic intermittent hypoxia elicits serotonin-dependent plasticity in the central neural control of breathing. J Neurosci 21: $5381-5388$

LOREDO JS, CLAUSEN JL, NELESEN RA, ANCOLIISRAEL S, ZIEGLER MG, DIMSDALE JE (2001) Obstructive sleep apnea and hypertension: Are peripheral chemoreceptors involved? Med Hypotheses 56: $17-19$

MOORE L (2000) Comparative human ventilatory adaptation to high altitude. Respir Physiol 121: 257276

NARKIEWICZ K, MONTANO N, COGLIATI C, VAN DE BORNE PJ, DYKEN ME, SOMERS VK (1998a) Altered cardiovascular variability in obstructive sleep apnea. Circulation 98: 1071-1077

NARKIEWICZ K, VAN DE BORNE PJ, MONTANO N, DYKEN ME, PHILLIPS BG, SOMERS VK (1998b) Contribution of tonic chemoreflex activation to sympathetic activity and blood pressure in patients with obstructive sleep apnea. Circulation 97: 943-945

NARKIEWICZ K, VAN DE BORNE PJ, PESEK CA, DYKEN ME, MONTANO N, SOMERS VK (1999) Selective potentiation of peripheral chemoreflex sensitivity in obstructive sleep apnea. Circulation 99: 1183-1189

NIELSEN AM, BISGARD GE, VIDRUK EH (1988) Carotid chemoreceptor activity during acute and sustained hypoxia in goats. J Appl Physiol 65: 17961802

OSANAI S, AKIBA Y, FUJIUCHI S, NAKANO H, MATSUMOTO H, OHSAKI Y, KIKUCHI K (1999) Depression of peripheral chemosensitivity by a dopaminergic mechanism in patients with obstructive sleep apnea syndrome. Eur Respir J 13: 418-423.

PENG YJ, PRABHAKAR NR (2003) Reactive oxygen species in the plasticity of breathing elicited by chronic intermittent hypoxia. J Appl Physiol 94: 2342-2349

PENG YJ, KLINE DD, DICK TE, PRABHAKAR NR (2001) Chronic intermittent hypoxia enhances carotid body chemoreceptor response to low oxygen. In: POON CS, KAZEMI H (eds) Frontiers in Modeling and Control of Breathing. New York: Kluwer Academic Press. pp: 33-38

PENG YJ, OVERHOLT JL, KLINE D, KUMAR GK, PRABHAKAR NR (2003) Induction of sensory longterm facilitation in the carotid body by intermittent hypoxia: Implications for recurrent apneas. Proc Natl Acad Sci USA 100: 10073-10078

QUAN SF, GERSH BJ (2004) Cardiovascular consequences of sleep-disordered breathing: Past, present and future: Report of a workshop from the National Center on Sleep Disorders Research and the National Heart, Lung, and Blood Institute. Circulation 109: 951-957

REEVES SR, GOZAL E, GUO SZ, SACHLEBEN LR, BRITTIAN KR, LIPTON AJ, GOZAL D (2003) Effect of long-term intermittent and sustained hypoxia on hypoxic ventilatory and metabolic responses in the adult rat. J Appl Physiol 95: 1767-1774

REY S, DEL RÍO R, ALCAYAGA J, ITURRIAGA R (2004a) Chronic intermittent hypoxia enhances cat chemosensory and ventilatory responses to hypoxia. J Physiol Lond 560: 577-586

REY S, DEL RÍO R, LEÓN CG, ITURRIAGA R (2004b) Modulatory effect of endothelin-1 on carotid chemoreception. Biol Res 37: R-56

SANTOLAYA RB, LAHIRI S, ALFARO RT, SCHOENE RB (1989) Respiratory adaptation in the highest inhabitants and highest Sherpa mountaineers. Respir Physiol 77: 253-262

SHIOMI T, GUILLEMINAULT C, SASANABE R, HIROTA I, MAEKAWA M, KOBAYASHI T (1996) Augmented very low frequency component of heart rate variability during obstructive sleep apnea. Sleep 19: $370-377$

SICA AL, GREENBERG HE, RUGGIERO DA, SCHARF SM (2000) Chronic-intermittent hypoxia: A model of sympathetic activation in the rat. Respir Physiol 121: 173-184

SMITH CA, BISGARD GE, NIELSEN AM, DARISTOTLE L, KRESSIN NA, FOSTER HV, DEMPSEY JA (1986) Carotid bodies are required for ventilatory acclimatization to chronic hypoxia. J Appl Physiol 60(3): 1003-1010

SMITH ML, MUENTER MK (2000) Effects of hypoxia on sympathetic neural control in humans. Respir Physiol 121: $163-171$

SOMERS VK, DYKEN ME, CLARY MP, ABBOUD FM (1995) Sympathetic neural mechanisms in obstructive sleep apnea. J Clin Invest 96: 1897-1904

TASK FORCE OF THE EUROPEAN SOCIETY OF CARDIOLOGY AND THE NORTH AMERICAN SOCIETY OF PACING AND ELECTROPHYSIOLOGY (1996) Heart rate variability. Standards of measurement, physiological interpretation, and clinical use. Eur Heart J 17: 354381

VALDÉS V, MOSQUEIRA M, REY S, DEL RÍO R, ITURRIAGA R (2003) Inhibitory effects of NO on carotid body: Contribution of neural and endothelial nitric oxide synthase isoforms. Am J Physiol (Lung Cell Molec Physiol) 284: L57-L68

WANG ZY, BISGARD GE (2002) Chronic hypoxiainduced morphological and neurochemical changes in the carotid body. Microsc Res Tech 59: 168-177

YE JS, TIPOE GL, FUNG PC, FUNG ML (2002) Augmentation of hypoxia-induced nitric oxide generation in the rat carotid body adapted to chronic hypoxia: An involvement of constitutive and inducible nitric oxide synthases. Pflugers Arch 444: 178-185

ZAPATA P, ITURRIAGA R (1997) Modulation of arterial chemoreceptor activity and its contribution to the hypoxic response. In: GONZÁLEZ L, CHARRIER R, LLANOS A, RAGGI LA (eds) Altiplano: Ciencia y Conciencia. Santiago: Ediciones Universidad de Chile. pp: $66-77$

ZAPATA P, LARRAÍN C (2005) How the carotid body works: Different strategies and preparations to solve different problems. Biol Res 38: 315-328 